\title{
IN VITRO ANTIOXIDANT ACTIVITY, IN VIVO ANTIPYRETIC AND ANTI-INFLAMMATORY ACTIVITIES OF PARONYCHIA CAPITATA L.
}

\author{
BOUZIDI SOUMIA ${ }^{1 *}$, BENKIKI NAIMA ${ }^{1}$, ALLAOUA ZINA ${ }^{2}$
}

${ }^{1}$ Départenent de Biologie, Faculté des Sciences de la Nature et de la vie, Laboratoire de Biotechnologie des Molécules Bioactives et de la Physiopathologie Cellulaire, Université de Batna-2, Batna, Algérie. ${ }^{2}$ Département de Chimie, Faculté des Sciences de la Matière, Laboratoire de Chimie et Chimie de l’Environnement (L.C.C.E), Université de Batna-1, Batna, Algérie. Email: bousoum40@yahoo.fr

Received: 01 November 2016, Revised and Accepted: 11 November 2016

ABSTRACT

Objective: The aim of this study is to evaluate the in vitro antioxidant activity of Paronychia capitata various extracts, acute toxicity, the in vivo antipyretic and anti-inflammatory activities of the n-butanol extract.

Methods: The antioxidant properties were tested using 2,2-diphenyl 1-picrylhydrazyl radical scavenging and $\beta$-carotene linoleic acid system, the total phenolic and flavonoid contents were determined. Furthermore, anti-inflammatory activity and antipyretic activity of the n-butanol extract were assessed on male Wistar rats at the dose levels $250,500 \mathrm{mg} / \mathrm{kg}$ body weight, using the egg albumin-induced edema, and brewer's yeast-induced pyrexia method, respectively.

Results: The n-butanol extract of $P$. capitata had considerably the highest antiradical activity with inhibitory concentration 50 value of $8.667 \mu$ g/ml.

Conclusion: The experimental data demonstrated that n-butanol extract of $P$. capitata possess significantly remarkable anti-inflammatory and antipyretic activities compared to the standard drugs.

Keywords: Caryophyllaceae, Flavonoid, Inflammation, Fever, Paronychia capitata.

(C) 2017 The Authors. Published by Innovare Academic Sciences Pvt Ltd. This is an open access article under the CC BY license (http://creativecommons. org/licenses/by/4. 0/) DOI: http://dx.doi.org/10.22159/ajpcr.2017.v10i3.15981

\section{INTRODUCTION}

Paronychia is a genus that belongs to the subfamily of Paronychioideae [1]. It is represented by five species in the flora of Algeria [2]. Paronychia capitata L. known under the name of (Atai el Djebel). The infusion of the aerial parts of the plant has been used in Spanish folk medicine to purify blood, regulate the circulation and treat gout, as well as an agent for dermatitis and as an expectorant $[3,4]$. It is also used as cholagogue, dermatologic, anti-infective, lithotritic, diuretic, digestive and antihypertensive [5,6]. Although there are no reports of the medicinal uses of $P$. capitata, the aerial parts of $P$. argentea Lam. are used in the Algerian popular medicine for the treatment of renal diseases, diabetes, and as diuretic. This plant is also used to treat stomach ulcers, anorexia, bladder and prostate diseases, and heart pains $[7,8]$. According to literature survey, no data are available about the therapeutic applications or the biological activity of $P$. capitata in Algeria. Therefore, this study examined the total phenolic and flavonoid contents, the antioxidant activity (AA) and the anti-inflammatory and antipyretic activities of various extracts of $P$. capitata collected from the East of Algeria.

P. capitata Lam. was collected in May 2015, in Batna, East of Algeria. All parts of the plant previously dried and ground into thin powder was macerated twice in $70 \%$ ethanol for $48 \mathrm{hrs}$ at room temperature. After filtration and evaporation of the solvent, the resulting aqueous phase undergoes a liquid-liquid extraction with petroleum ether then ethyl acetate, and final n-butanol. Evaporation dry organic solutions raised the following extracts: The petroleum $P$. capitata ether extract, ethyl acetate extract and the butanol extract. Aqueous extract was prepared by boiling the air-dried powdered plant in distilled water for 10 minutes and then cooled to room temperature overnight. The aqueous extract was filtered using Whatman filter paper. The filtrate was concentrated using rotary evaporator and lyophilized.
The total phenolic content of the plant extracts was determined according to the Folin-Ciocalteu method [9]. The results were calculated using the standard calibration curve of gallic acid $(0-200 \mu \mathrm{g} / \mathrm{ml})$ and expressed as micrograms of gallic acid equivalents per milligrams of dry extract ( $\mu \mathrm{g} \mathrm{GAE} / \mathrm{mg}$ of extract). Colorimetric aluminum chloride method was used for flavonoid determination [10]. Total flavonoid contents were calculated from a calibration curve obtained by preparing quercetin solutions in methanol $(0-40 \mu \mathrm{g} / \mathrm{ml})$, and expressed in microgram of quercetin equivalents per milligrams of dry extract ( $\mu \mathrm{g} \mathrm{QE} / \mathrm{mg}$ of extract).

The free radical scavenging activity of the extracts was measured in vitro by 2,2- diphenyl 1-picrylhydrazyl (DPPH) essay [11]. The AA of the extracts was expressed as inhibitory concentration (IC50) in $(\mu \mathrm{g} / \mathrm{ml})$ and quercetin was used as reference standard. To assess lipid peroxidation activity of the samples, $\beta$-carotene bleaching essay was carried out according to the method described by Kartal et al.[12] After the incubation period, the absorbance was measured at $490 \mathrm{~nm}$ at 0 , $1,2,4,6,24,26,28$, and 48 hrs. All determinations were performed in triplicate. The total AA was calculated.

Young male adult Wistar albino rats (150-200 g) were used in these experiments. They were housed in plastic cage at temperature of $(25 \pm 2)^{\circ} \mathrm{C}$ with a 12 light/dark cycle, respectively, before and during the experiment, and had free access to drinking water. Animals were fed with a standard diet. The oral acute toxicity test was performed using ten healthy rats that were allocated in two groups. From $12 \mathrm{hrs}$ before to $4 \mathrm{hrs}$ after the oral administration, the animals were fasted (animals had water but not food) and weighed. The essay was followed as Organization for Economic Co-operation and Development Guideline 425 [13]. The control group received normal saline $10 \mathrm{ml} / \mathrm{kg}$ body weight by gavage, whereas the exposed groups (Groups 1) received $2000 \mathrm{mg} / \mathrm{kg} n$-butanol extracts of $P$. capitata. Animals were observed during the first 30 minutes, 2, 4, and 6 hrs after treatment, and daily 
thereafter for a total of 14 days in terms of weight loss, mortality, changes in behavior, skin, eyes, and fur.

The anti-inflammatory effect was assessed in acute inflammation method already described by Anosike et al. [14] Initially, normal paw thickness of each rat was noted. Inflammation was produced by injection of $0.1 \mathrm{ml}$ of undiluted fresh egg albumin into the sub planter surface of the right hand paw of each rat $1 \mathrm{hr}$ after oral administration of $P$. capitata butanol extract (PCBU 250, $500 \mathrm{mg} / \mathrm{kg}$ body weight), or diclofenac (Phamalliance, Ouled-Fayet, Algiers- Algeria) (DICLO; $30 \mathrm{mg} / \mathrm{kg}$ body weight). The control group was received $10 \mathrm{ml} / \mathrm{kg}$ of normal saline. The paw thickness was measured before injecting egg albumin and after 30, 60, 120, 180, 240, and 300 minutes using Vernier caliper (Shanghai Shenhan China).

Before the start of the antipyretic activity experiment, the animals were divided into four groups, each of five rats. The rectal temperature of each one was recorded using digital thermometer (VEDO Lente- Artsana, Italy) and then pyrexia was induced by subcutaneous injection of $20 \% \mathrm{w} / \mathrm{v}$ of brewer's yeast $(10 \mathrm{ml} / \mathrm{kg})$ in normal saline [15]. All groups were fasted overnight, after $18 \mathrm{hrs}$ rectal temperature of each rat was recorded. Group I received normal saline $(10 \mathrm{ml} / \mathrm{kg})$ as a negative control, Group II received paracetamol (Winthrop Pharma Saidal. Oued-Smar. Algeria) (PARA $150 \mathrm{mg} / \mathrm{kg}$ ) as a standard drug [16] while the remaining Groups III and IV received 250, $500 \mathrm{mg} / \mathrm{kg}$ PCBU, respectively. After drug administration, the rectal temperature was then recorded over 5 hrs.

The data of the in vivo activities were analyzed using one-way analysis variance (ANOVA) followed by Dunnett's test for individual comparison of groups with control. All values were expressed as mean \pm standard error of the mean $(n=5)$. Values were considered statistically significant when $\mathrm{p}<0.01$. The in vitro data were reported as mean \pm standard deviation of three replicates $(n=3)$. The data were analyzed using oneway ANOVA and Newman-Keuls post-test.

The amount of total phenolics varied in different extracts and ranged from 05.140 to $32.238 \mu \mathrm{g} \mathrm{GAE} / \mathrm{mg}$ of dry extract. The results indicated that PCBU (32.238 $\pm 1.404 \mu \mathrm{g} \mathrm{GAE} / \mathrm{mg}$ ) has the highest phenolic content, and the $P$. capitata ethyl acetate extract $(05.140 \pm 0.132 \mu \mathrm{g} \mathrm{GAE} / \mathrm{mg})$ has the lowest phenolic contents. However, the highest flavonoid contents $(6.077 \pm 0.443 \mu \mathrm{g} \mathrm{QE} / \mathrm{mg}$ of dry extract) was found in $P$. capitata aqueous extract among the various extracts of $P$. capitata as shown in Table 1.

The extracts of $P$. capitata were screened for their possible AA by two complementary test systems; the DPPH free radical scavenging and the $\beta$-carotene/linoleic acid system. For the DPPH radical scavenging activity, all the sample extracts exhibited significant dose-dependent activity. Moreover, the results indicated in Table 1 show that the butanol fraction PCBU has the lowest IC50 $(8.667 \pm 0.577 \mu \mathrm{g} / \mathrm{ml})$ among extracts of $P$. capitata which is comparable to the one of standard quercetins. On the other hand, the comparable $\beta$-carotene bleaching rates of the positive control butylated hydroxytoluene (BHT) and P. capitata different extracts (Table 1). The butanol fraction PCBU shows the maximum inhibition $(84.92 \%)$ which is close to the positive control BHT.

Acute oral toxicity; during the 14 days treatment, no significant difference $(\mathrm{p}>0.01)$ was recorded between the experimental and control group. The safety of the extract is evidenced by the high LD50

Table 1: Total phenolic and flavonoid contents, effects of $P$. capitata $\mathrm{L}$. various extracts and positive control (quercetin, BHT) on the in vitro free radical (DPPH) scavenging and in $\beta$-carotene/linoleic acid system

\begin{tabular}{lllll}
\hline EXTRACTS & TOTAL PHENOLIC $^{\mathrm{a}}$ & TOTAL FLAVONOID $^{\mathrm{b}}$ & IC50 $(\boldsymbol{\mu g} / \mathbf{m l})^{\text {ANTIOXIDANT ACTIVITY } \text { (\%) }}$ \\
\hline PCBU & $32.238 \pm 1.404^{\mathrm{a}}$ & $3.481 \pm 0.185^{\mathrm{a}}$ & $08.667 \pm 0.577^{\mathrm{a}}$ & $84.916 \pm 2.401^{\mathrm{a}}$ \\
PCAC & $05.140 \pm 0.132^{\mathrm{c}}$ & $2.648 \pm 0.754^{\mathrm{a}}$ & $11.333 \pm 0.577^{\mathrm{b}}$ & $74.082 \pm 1.470^{\mathrm{b}}$ \\
PCEP & $29.062 \pm 0.884^{\mathrm{c}}$ & $3.113 \pm 0.581^{\mathrm{a}}$ & $24.046 \pm 1.000^{\mathrm{c}}$ & $66.540 \pm 5.182^{\mathrm{b}}$ \\
PCAQ & $10.199 \pm 2.24^{\mathrm{b}}$ & $6.077 \pm 0.443^{\mathrm{b}}$ & $16.000 \pm 0.000^{\mathrm{d}}$ & $42.852 \pm 2.779^{\mathrm{c}}$ \\
QUERCETIN & $/$ & $/$ & $1.149 \pm 0.0004$ & $/$ \\
BHT & $/$ & $/$ & $/$ & $99.167 \pm 1.056$ \\
\hline
\end{tabular}

Mean \pm SD ( $n=3)$. ${ }^{a}$ Expressed as microgram of gallic acid per milligram dry extract, ${ }^{b}$ Expressed as microgram of quercetin per milligram dry extract. Means in the same column sharing different letters are significantly different P<0.05, BHT: Butylated hydroxytoluene, DPPH: 2,2-diphenyl 1-picrylhydrazyl, SD: Standard deviation, IC50: Inhibitory concentration, P. capitata: Paronychia capitata, PCEP: P. capitata ether extract, PCAC: P. capitata ethyl acetate extract, PCAQ: P. capitata aqueous extract

Table 2: Anti-inflammatory effect of diclofenac and the n-butanol extract of $P$. capitata against egg albumin-induced paw oedema in rats

\begin{tabular}{|c|c|c|c|c|c|c|c|}
\hline \multicolumn{8}{|c|}{ PAW THICKNESS \pm SEM $(\mathrm{mm})$} \\
\hline TREATMENT & DOSE (mg/kg) & 30 minutes & $1 \mathrm{hr}$ & $2 \mathrm{hrs}$ & 3 hrs & $4 \mathrm{hrs}$ & $5 \mathrm{hrs}$ \\
\hline Control & $10 \mathrm{ml} / \mathrm{kg}$ & $9.340 \pm 0.145$ & $7.678 \pm 0.134$ & $6.534 \pm 0.151$ & $6.196 \pm 0.109$ & $4.936 \pm 0.158$ & $4.070 \pm 0.077$ \\
\hline DICLO & 30 & $6.418 \pm 0.157^{* * *}$ & $5.340 \pm 0.121^{* * *}$ & $4.492 \pm 0.193^{* * *}$ & $3.402 \pm 0.097^{* * *}$ & $3.120 \pm 0.138^{* * *}$ & $2.710 \pm 0.187^{* * *}$ \\
\hline PCBU & 500 & $7.314 \pm 0.185^{* * *}$ & $6.074 \pm 0.106^{* * *}$ & $4.714 \pm 0.237^{* * *}$ & $3.958 \pm 0.181^{* * *}$ & $2.996 \pm 0.214^{* * *}$ & $3.358 \pm 0.197^{* *}$ \\
\hline PCBU & 250 & $7.604 \pm 0.036^{* * *}$ & $6.198 \pm 0.066^{* * *}$ & $4.712 \pm 0.210^{* * *}$ & $3.904 \pm 0.095^{* * *}$ & $3.352 \pm 0.182^{* * *}$ & $3.366 \pm 0.228^{*}$ \\
\hline
\end{tabular}

All values were expressed as mean \pm SEM $(\mathrm{n}=5)$. *Significantly different from the control at the corresponding time P<0.01, P. capitata: Paronychia capitata, SEM: Standard error of the mean, PCBU: P. capitata butanol extract, ${ }^{* *}$ moderately significant compared with the control $\mathrm{P}<0.01,{ }^{* * *}$ highly significant compared with the control $\mathrm{P}<0.001$.

Table 3: Antipyretic activity of n-butanol extract of $P$. capitata and paracetamol on yeast induced pyrexia in rats

\begin{tabular}{|c|c|c|c|c|c|c|c|c|}
\hline \multicolumn{9}{|c|}{ RECTAL TEMPERATURE $\left({ }^{\circ} \mathrm{C}\right)$ BEFORE AND AFTER TREATMENT } \\
\hline TREATMENT & $0 \mathrm{hr}$ & $18 \mathrm{hrs}$ & $\begin{array}{l}18 \text { hrs } \\
30 \text { minutes }\end{array}$ & 19 hrs & 20 hrs & 21 hrs & 22 hrs & $23 \mathrm{hrs}$ \\
\hline Control & $36.70 \pm 0.341$ & $38.10 \pm 0.161$ & $38.10 \pm 0.161$ & $38.10 \pm 0.161$ & $38.00 \pm 0.162$ & $38.00 \pm 0.171$ & $38.00 \pm 0.171$ & $37.90 \pm 0.172$ \\
\hline Paracetamol & $36.54 \pm 0.258$ & $37.88 \pm 0.222$ & $37.74 \pm 0.224 \mathrm{~ns}$ & $37.50 \pm 0.164^{* * *}$ & $37.20 \pm 0.176^{* * *}$ & $36.92 \pm 0.196^{* * *}$ & $36.76 \pm 0.206^{* * *}$ & $36.60 \pm 0.230^{* * *}$ \\
\hline PCBU500 mg $/ \mathrm{kg}$ & $36.26 \pm 0.304$ & $37.95 \pm 0.189$ & $37.84 \pm 0.112 \mathrm{~ns}$ & $37.60 \pm 0.148^{* *}$ & $37.20 \pm 0.189 * * *$ & $37.00 \pm 0.216^{* * *}$ & $36.68 \pm 0.228^{* * *}$ & $36.44 \pm 0.290^{* * *}$ \\
\hline PCBU250 mg $/ \mathrm{kg}$ & $36.24 \pm 0.299$ & $37.60 \pm 0.158$ & $37.64 \pm 0.156 \mathrm{~ns}$ & $37.44 \pm 0.160 \mathrm{~ns}$ & $37.18 \pm 0.168^{*}$ & $37.02 \pm 0.180^{* *}$ & $36.82 \pm 0.228^{* *}$ & $36.70 \pm 0.225^{* *}$ \\
\hline
\end{tabular}

All values were expressed as mean \pm SEM $(\mathrm{n}=5)$. *Significantly different from the control at the corresponding time $\mathrm{P}<0.01$, SEM: Standard error of the mean, $P$. capitata:

Paronychia capitata, PCBU: P. capitata butanol extract, ${ }^{* *}$ moderately significant compared with the control $\mathrm{P}<0.01$, ${ }^{* * *}$ highly significant compared with the control P<0.001. 
value of the butanol extract ( $>2000 \mathrm{mg} / \mathrm{kg}$ ). The investigation of the anti-inflammatory activity of $\mathrm{n}$-butanol extract of $P$. capitata $\mathrm{L}$. was assessed using egg albumin induced paw edema method. The study showed that the extract had a significant effect on inflammation and reduced clearly the swelling. As shown in Table 2, the n-butanol fraction evoked a non-dose related anti-inflammatory activity and inhibited significantly the increase of paw edema from 30 minutes to 5 hrs. The maximum inhibitory effect (96.63\%) was recorded at the dose $500 \mathrm{mg} / \mathrm{kg}$ of the n-butanol extract after $5 \mathrm{hrs}$. The effect of the $n$-butanol fraction on yeast-induced pyrexia is presented in Table 3. Treatment with $n$-butanol extract of $P$. capitata revealed a significant decrease $(\mathrm{p}<0.01)$ in rectal temperature between 2 and 5 hrs after administration, in a dose-dependent manner when compared to the control The antipyretic effect was observed from the first hour at the dose of $500 \mathrm{mg} / \mathrm{kg}$ and paracetamol (150 mg/kg), which was further maintained for $5 \mathrm{hrs}$. However, at the $250 \mathrm{mg} / \mathrm{kg}$ dose of $n$-butanol extract of $P$. capitata showed a moderate antipyretic activity after 2 hrs.

The results of this study proved the antioxidant anti-inflammatory and antipyretic activities of $P$. capitata extracts. Moreover, this study indicates that this plant may be useful in the protection against inflammatory diseases. However, phytochemical study is necessary to identify the active principles and exact mechanisms of action.

\section{ACKNOWLEDGMENTS}

The authors would like to thank the DGRSDT of the Algerian Minister of Higher Education and Scientific Research for providing a research grant.

\section{REFERENCES}

1. Core EL. The North American species of paronychia. Am Midl Nat 1941;263:69-7.

2. Quezel P, Santa S. Nouvelle Flore de 1'Algérie et Des Régions Désertiques Méridionales. Vol. 1-2. Paris: CNRS; 1963.

3. González-Tejero MR, Molero-Mesa J, Casares-Porcel M, Martínez Lirola MJ. New contributions to the ethnopharmacology of Spain. J Ethnopharmacol 1995;45(3):157-65.

4. Alcazar MD, Garcia C, Rivera D, Obon C. Lesser-known herbal remedies as sold in the market at Murcia and Cartagena Spain. J Ethnopharmacol 1990;28(2):243-7.

5. Nunez D, Obon DE, Castro C. Ethnopharmacology of Murcia (SE Spain), Médicaments et Aliments: L'Approche Ethnopharmacologique Actes du $2^{\text {e }}$ Colloque Eurogen d'Ethnopharmacologie et de la 11 Conférence Internationale d'Ethnomédecine 1993. p. 215-39.

6. Novaretti R, Lemordant D. Plants in the traditional medicine of the Ubaye Valley. J Ethnopharmacol 1990;30(1):1-34.

7. Sait S, Hamri-Zeghichi S, Boulekbache-Makhlouf L, Madan K, Rigou P, Brighenti V, et al. HPLC-UV/DAD and ESI-MS(n) analysis of flavonoids and antioxidant activity of an Algerian medicinal plant: Paronychia argentea Lam. J Pharm Biomed Anal 2015;111:231-40.

8. Bouanani S, Henchiri C, Migianu-Griffoni E, Aouf N, Lecouvey M. Pharmacological and toxicological effects of Paronychia argentea in experimental calcium oxalate nephrolithiasis in rats. J Ethnopharmacol 2010;129(1):38-45.

9. Li HB, Cheng KW, Wong CC, Fan KW, Chen F, Jiang Y. Evaluation of antioxidant capacity and total phenolic content of different fractions of selected microalgae. Food Chem 2007;102:771-6.

10. Bahorun T, Gressier B, Trotin F, Brunet C, Dine T, Luyckx M, et al. Oxygen species scavenging activity of phenolic extracts from hawthorn fresh plant organs and pharmaceutical preparations. Arzneimittelforschung 1996;46(11):1086-9.

11. Mansouri A, Embarek G, Kokkalou E, Kefalas P. Phenolic profile and antioxidant activity of the Algerian ripe date palm fruit (Phoenix dactylifera). Food Chem 2005;89:411-20.

12. Kartal N, Sokmen M, Bektas T, Dimitra D, Moschos P, Atalay S. Investigation of the antioxidant properties of Ferula orientalis L. Using a suitable extraction procedure. Food Chem2007;100(2):584-9.

13. Kumar VK, Lalitha KG. Acute oral toxicity studies of Anacyclus pyrethrum dc root in albino rats. Int $\mathrm{J}$ Pharm Pharm Sci 2013;5(4):675-8.

14. Anosike CA, Obidoa O, Ezeanyika LU. The anti-inflammatory activity of garden egg (Solanum aethiopicum) on egg albumin-induced oedema and granuloma tissue formation in rats. Asian Pac J Trop Med 2012;5(1):62-6.

15. Junaid N, Vikas G, Prithviraj C, Pawan K. Anti-inflammatory and antipyretic activity of Aleurites moluccausa leaves. AJPCR 2010;3:35-7.

16. Benhouda A, Yahia M. Toxicity, analgesic and anti-pyretic activities of methanolic extract from hyoscyamusalbus' leaves in albinos rats. Int J Pharm Pharm Sci 2014;6(3):121-7 